\title{
APRENDIZAGEM SIGNIFICATIVA NO ENSINO DE BIOLOGIA DO ENSINO MÉDIO
}

\section{ARTIGO ORIGINAL}

OLIVEIRA, Cleber Macedo de ${ }^{1}$

BERNARDO, Ana Maria Guimarães ${ }^{2}$

NOGUEIRA, Natiélia Oliveira ${ }^{3}$

OLIVEIRA, Cleber Macedo de. BERNARDO, Ana Maria Guimarães. NOGUEIRA, Natiélia Oliveira. Aprendizagem significativa no ensino de biologia do Ensino Médio. Revista Científica Multidisciplinar Núcleo do Conhecimento. Ano 05, Ed. 02, Vol. 02, pp. 129-152. Fevereiro de 2020. ISSN: 2448-0959, Link de acesso: https://www.nucleodoconhecimento.com.br/educacao/biologia-do-ensino$\underline{\text { medio }}$

\section{RESUMO}

Aprendizagem significativa é definida como o modelo de aprendizado no qual o conhecimento novo interage com os conhecimentos prévios do aluno. Nesse modelo, aluno e professor são responsáveis pelo aprendizado, tendo como o principal benefício o tempo de duração do conteúdo aprendido. Nesse modelo de aprendizado não ocorre a memorização dos conteúdos e por isso a sua grande vantagem. Diante

${ }_{1}$ Doutor em Entomologia pela Universidade Federal de Viçosa, Docente do Instituto Federal de Educação, Ciência e Tecnologia do Amapá - Campus Porto Grande.

2 Doutora em Fitotecnia pela Universidade Federal de Viçosa, Docente do Instituto Federal de Educação, Ciência e Tecnologia do Amapá - Campus Porto Grande.

${ }^{3}$ Doutora em Produção Vegetal pela Universidade Federal do Espírito Santo; Docente do Instituto Federal de Educação, Ciência e Tecnologia do Espirito Santo - Campus Ibatiba. 
disso, o trabalho teve como objetivo desenvolver um modelo de experimento com metodologia significativa envolvendo o tema osmose. Foi elaborado e testado um roteiro de experimento com o tema osmose bem como um questionário para discussão entre professores e alunos com possíveis resultados do experimento, caso os professores tenham dificuldade na realização da prática. Os resultados dos experimentos são possíveis de discussão na área de biologia, matemática e informática de forma interdisciplinar.

Palavras-chave: Estratégias de ensino, ensino de ciências, experimentação, interdisciplinaridade, aulas experimentais.

\section{INTRODUÇÃO}

Para que os alunos se interessem pelo conteúdo estudado, os professores devem buscar alternativas metodológicas que os atraiam. Leão (1999) relata a utilização de metodologias de ensino tradicional no ensino Fundamental e Médio, por muitos professores. Para Carraher; Carraher e Schliemann (1985) esse modelo de ensino é entendido como sendo o modelo no qual um conjunto de informações são transmitidas dos professores para os alunos, e esta não é a forma de ensino que tem levado a um aprendizado de fato. No modelo de ensino tradicional, as aulas são expositivas, em sua quase totalidade, sem a interação com os alunos. Esse modelo de aula é marcado pelo verbalismo e pela memorização. No modelo tradicional de ensino os alunos são meros ouvintes e ao invés de aprenderem, eles apenas memorizam o que o professor verbaliza. Essa forma de memorização leva a um "aprendizado" por um curto período, apenas o suficiente para realizarem as provas. Para efetivamente ocorrer a aprendizagem, outros modelos de ensino têm sido propostos por diversos autores, como por exemplo, a aprendizagem significativa.

A aprendizagem torna-se mais significativa quando o novo conteúdo se incorpora aos conhecimentos prévios do aluno e passa, a partir de então, a relacionar-se com os conhecimentos prévios. Dessa forma, diversos autores têm relatado que tal modelo de aprendizagem leva a um conhecimento mais duradouro e persistente quando comparado com à memorização (AUSUBEL; NOVAK; HANESIAN,1980; PELIZZARI 
et. al., 2002). Pelizzari et al. (2002) discutiram que para ocorrer a aprendizagem significativa ou ativa, como também é chamada, é necessário atender a duas condições básicas, uma inerente ao aluno e outra dependente do conteúdo. A primeira condição é que o aluno deverá estar disposto a aprender e não somente a memorizar. Já a segunda condição é que o conteúdo escolar precisa, necessariamente, ser potencialmente significativo. Pelizzari et al. (2002) a segunda condição, impede que o professor utilize esse modelo de aula em todos os momentos, pois nem todos os conteúdos são potencialmente significativos. Até o presente momento podemos enfrentar problemas na aplicação da metodologia ativa com alguns conteúdos, entretanto com os avanços das Tecnologias de Informação e Comunicação (TIC) possivelmente poderemos utilizar novas estratégias para ensinar e aprender. Um avanço das TIC a ser citado são os laboratórios de aprendizagem, que estão se tornando muito presentes no ambiente escolar, possibilitando a realização de aulas práticas em escolas que não apresentam laboratórios de química e biologia, por exemplo.

Smith (1998) coloca as práticas no ensino de Ciência como sendo de grande importância e que para ela deveria ocupar lugar de destaque no ensino de tal conteúdo. Porém, devemos elaborar práticas que não se pautem apenas no caráter superficial, mecânico e repetitivo, no qual o aluno apenas é exposto a um roteiro que indica o que deve ser feito sem desafiá-lo a entender as razões do porquê está fazendo. Os experimentos devem ser dinâmicos, processuais e significativos (SILVA; ZANON, 2000). As práticas devem servir como um momento extra de aprendizado de um conteúdo, de forma que a experiência possa ser utilizada para fixação do conteúdo. Com isso, as práticas não são somente ilustração da teoria, mas correspondem também ao momento de aprendizado (CAPELETTO, 1992).

As experimentações foram definidas por Moraes (1998) como uma maneira de testar hipóteses, confirmando ou refutando tais ideias sobre um assunto. Os experimentos podem ser realizados tanto para testar hipóteses, no caso de dúvidas sobre o assunto, mas pode também ser utilizado para demonstração da veracidade de uma lei. Moraes 
(1998) define o experimento construtivista como sendo a construção do conhecimento por meio da prática da interação entre o aprendiz e o meio.

As práticas construtivistas apresentam além dos conceitos anteriores, a multidisciplinaridade, sendo que nesse caso de experimento é possível demonstrar a interpelação entre as disciplinas (MORAES, 1998). Nesse sentido, é preciso que se consiga elaborar experimentos com temas amplos e abordá-los de forma interdisciplinar. Essa interação interdisciplinar é uma metodologia para tentar superar a pedagogia da separação do saber (JAPIASSU, 1976). O trabalho interdisciplinar torna o aprendizado integrado e interessante para o discente.

A interdisciplinaridade pode ser entendida como a conexão ente dois ou mais componentes curriculares (FAZENDA, 1994). A interdisciplinaridade não pode ser confundida com o trabalho de dois ou mais componentes curriculares no mesmo assunto, mas esses devem de fato interagir entre si. Os docentes devem discutir para definir as ações a serem implementadas para atender ao objetivo comum da atividade de forma a torná-la interdisciplinar.

Diante dos problemas citados, objetivou-se elaborar e testar um roteiro de atividade experimental que abordem o tema osmose para ser utilizado no ensino da disciplina de Biologia para o Ensino Médio.

Os objetivos específicos do trabalho são:

1. Elaborar um roteiro experimental que envolva o conteúdo de biologia com a utilização de materiais encontrados no ambiente escolar ou de baixo custo;

2. Validar o roteiro de forma a anotar os possíveis resultados encontrados pelos professores;

3. Elaborar pontos chave do tema do experimento de forma a instigar a discussão entre os discentes/docentes.

4. Elaboração de ficha para avaliação da efetividade do experimento no aprendizado significativo. 


\section{REVISÃO DE LITERATURA}

\subsection{APRENDIZAGEM SIGNIFICATIVA}

Mesmo nos dias atuais, mesmo com a disponibilidade de diversas ferramentas tecnológicas para o ensino, muitos alunos ainda apresentam grandes dificuldades em entender a Ciência instruída nas escolas. Esta área de ensino, mesmo envolvida no cotidiano de todos, para muitos, alunos e às vezes até mesmo para alguns professores, é difícil fazer a correlação entre os acontecimentos cotidianos com os assuntos de biologia. Por isso, muitos alunos têm colocado o estudo de Biologia como algo difícil e complicado.

Com os avanços tecnológicos, é exigido dos professores a utilização de ferramentas extras em suas aulas, como por exemplo, laboratórios virtuais, vídeos, experimentos virtuais, atividades experimentais, entre outros recursos, com o intuito de manter o foco dos alunos durante as aulas. Os alunos estão cada dia mais dispersos e desinteressados pelas aulas expositivas e com esse comportamento, torna-se cada vez mais difícil motivá-los, ainda mais em salas de aula com poucos recursos, tecnológicos e não tecnológicos.

Nesse sentido, Araújo e Abib (2003) relatam que uma das possíveis soluções para os problemas citados anteriormente é o desenvolvimento de uma educação voltada para o aluno, na qual o aluno participe das atividades de forma plena. Para essa modalidade de ensino, é preciso um treinamento do professor e a disponibilização de materiais para tais atividades. Esse é o chamado modelo de ensino significativo.

A aprendizagem significativa ou aprendizagem ativa é representada pela interação entre os conhecimentos anteriores do aluno com os novos conhecimentos (AUSUBEL; NOVAK; HANESIAN, 1980; MEZZARI, 2011). Através dessa interação de conhecimentos, o conhecimento prévio toma um novo significado, tornando se mais amplo e o conhecimento novo toma um significado para o aprendiz. Dessa forma, a cada novo conhecimento adquirido de forma significativa, ocorre uma transformação dos conhecimentos anteriores e com isso, os novos conhecimentos adquirem uma 
maior estabilidade cognitiva. Uma das estratégias discutidas por diversos autores para promoverem a aprendizagem ativa é a aplicação de atividades que explorem os alunos a resolverem questões, a respeito do conteúdo que está sendo trabalhado (BONWELL; EISON, 1991; SILBERMAN, 1996).

Ausubel, Novak e Hanesian (1980) propuseram a separação da aprendizagem em duas classes: aprendizagem significativa e aprendizagem memorística. A primeira, como definida anteriormente, apresenta como principal vantagem a persistência do conteúdo aprendido, sendo que nesse caso o conteúdo é assimilado e lembrado por um longo período. $\mathrm{O}$ aluno mesmo não utilizando de tais conhecimentos, caso venha a "esquecer" o que aprendeu, o processo de reaprendizagem é muito mais rápido e fácil, comparado ao modelo memorístico. A segunda aprendizagem é baseada na memorização e na repetição. Dessa forma, passado um tempo sem utilização de tal conteúdo, o aprendiz é capaz de esquecer tudo, ou quase tudo que foi memorizado. Para que ocorra a reaprendizagem, o aluno precisa necessariamente aprender novamente como se nunca tivesse tido contato com aquele conteúdo.

Fracalanza; Amaral; Gouveia (1986) propuseram a substituição do modelo tradicional de aulas expositivas e da substituição da grande maioria dos livros didáticos que estimulam esse modelo tradicional de ensino, por práticas. A experimentação é o momento de conexão entre a teoria e a prática, momento no qual os alunos são capazes de observar os fenômenos e os processos naturais, de forma a elaborar hipóteses e alinhar o conhecimento científico ao conhecimento cotidiano (LIMA, JÚMIOR; BRAGA, 1999).

A aplicação de metodologias de aprendizagem significativa é uma forma de motivar os alunos e manter a atenção dos mesmos. Segundo Moreira e Masini (2001) a aprendizagem significativa ocorre quando os aprendizes se tornam proativos na atividade de construção de sua aprendizagem. A experimentação oportuniza a formulação de problemas do cotidiano pelos alunos e com isso permite a contextualização e o incitamento de questionamentos e investigação (GUIMARÃES, 2009). Dessa forma, a experimentação é uma ferramenta de aprendizado significativo, 
que tem demonstrado grande efetividade no processo de aprendizagem com alunos do Ensino Fundamental e Médio.

Nesse contexto, levando em consideração o provérbio do filósofo chinês Confúcio que diz: "o que eu ouço, eu esqueço, o que eu vejo, eu lembro, o que eu faço, eu compreendo". Silberman elaborou uma modificação do provérbio citado para melhor entendimento das metodologias ativas de aprendizagem, que traduzindo, diz que:

- $[\ldots]$ O que eu ouço, eu esqueço;

- O que eu ouço e vejo, eu me lembro;

- O que eu ouço, vejo e pergunto ou discuto, eu começo a compreender;

- O que eu ouço, vejo, discuto e faço, eu aprendo desenvolvendo conhecimento e habilidade;

- O que eu ensino para alguém, eu domino com maestria (SILBERMAN, 1996, p.83).

Seguindo o que diz o provérbio chinês e a reformulação de Silberman (1996), estimulando os alunos a ouvir, ver, questionar, discutir e ensinar, estaremos no caminho correto para uma aprendizagem ativa ou aprendizagem significativa. Dessa forma, a utilização de práticas de experimento tem sido uma proposta adotada em diversas áreas de ensino, de forma a promover a integração da teoria com a prática e reforçar o conteúdo aprendido, além de permitir novos conhecimentos. Alves e Stachak (2005) citam que a utilização de experimentos no ensino da educação básica tem sido uma ferramenta de grande importância no processo ensino-aprendizagem. Existe uma diversidade de trabalhos que discutem a realização de atividades práticas, experimentos, no ensino de Ciências Naturais (Física, Química e Biologia) (LAVONEN et al., 2004; GALIAZZI et al., 2001; SILVA; ZANON, 2000; ARRUDA; LABURÚ, 1996). Todos ressaltam a importância de tais práticas no ensino de tais componentes curriculares. Portanto, essa ferramenta é importante, pois leva a discussão de ideias e conceitos entre os alunos e com isso desperta no aluno uma curiosidade levando-o a participar da aula e a aprender de forma significativa. 
Portanto, sabe-se que é importante utilizar experimentos no ensino de conteúdo de disciplinas das Ciências Naturais. Porém, ainda não foi definido aqui o que de fato são os experimentos. Os experimentos correspondem a um método científico que tem por objetivo provocar observações, em condições específicas, de um fenômeno com a finalidade de se provar uma hipótese, ou ainda, a experimentação pode ser vista como um conjunto de processos utilizados para testar uma hipótese (VIANNA, 2001). Hodson (1998) afirma que as experimentações podem ser realizadas em outros ambientes ademais dos laboratórios, como por exemplo, atividades de campo, laboratórios de informática ou em estudos em museus.

Fica ainda mais evidente a relevância dos experimentos no ensino das ciências quando analisamos o que está escrito nos Parâmetros Curriculares Nacionais Ensino Médio:

Para o aprendizado científico, matemático e tecnológico, a experimentação, seja ela de demonstração, seja de observação e manipulação de situações e equipamentos do cotidiano do aluno e até mesmo a laboratorial, propriamente dita, é distinta daquela conduzida para a descoberta científica e é particularmente importante quando permite ao estudante diferentes e concomitantes formas de percepção qualitativa e quantitativa, de manuseio, observação, confronto, dúvida e de construção conceitual. A experimentação permite ainda ao aluno a tomada de dados significativos, com as quais possa verificar ou propor hipóteses explicativas e, preferencialmente, fazer previsões sobre outras experiências não realizadas (BRASIL, 1999, p.52-53).

Para o máximo aproveitamento das atividades experimentais é necessário que o professor disponha de uma gama de instrumentos para realização do mesmo. É necessário que o docente tenha realizado uma abordagem do assunto com a turma e que no início do experimento seja realizada uma recapitulação do assunto, dos pontos importantes do tema de forma a envolver todos os alunos no experimento. Também é recomendado que o professor disponha de um roteiro para que possa nortear o andamento dos trabalhos. É importante que os estudantes tenham a percepção das 
atividades a serem realizas e não somente sigam um roteiro pré-estabelecido. Experimentos nos quais os alunos somente executam o que foi programado, não são ferramentas efetivas para a aprendizagem significativa. Esses experimentos são chamados de "receita de bolo" pelos alunos e pouco contribuem para o processo efetivo de aprendizagem (MOREIRA; DINIZ, 2003).

Para melhor aprendizagem dos alunos, é indicado que o professor disponha de alguns minutos para que a turma possa analisar os instrumentos disponíveis para formularem possíveis formas de testar as hipóteses previstas no roteiro, ou criadas de antemão com os alunos. Diante da discussão dos possíveis experimentos, o professor deverá indagar sobre os possíveis problemas ou pontos considerados errados durante a execução do experimento de tal forma que todos entendam o porquê da realização do experimento da maneira como foi planejada. No roteiro, o docente deve dispor de um cronograma de execução para que todas as tarefas, na medida do possível, sejam executadas no mesmo dia e ao final do experimento deve-se prever um tempo de discussão para as conclusões. Essa discussão final dos resultados é fundamental para a aprendizagem significativa.

Nos experimentos que os docentes informam o tema a ser trabalho em sala nos dias posteriores, ele estimula a busca por informações pelos alunos, ampliando dessa forma o período que o aluno está estudando (GRISALES-FRANCO; GONZÁLEZAGUDELO, 2009; SÁ; MOURA, 2008). Com isto, o professor deixa a posição de único responsável pela construção do conhecimento e agora passa a compartilhar essa tarefa com o aluno.

Nesse contexto, uma das dificuldades enfrentadas pelos professores é a excessiva carga horária e com isso, não dispõem de tempo para elaboração dos experimentos e dos roteiros (PAGOTTO; VIANA, 1991; SILVA; ZANON, 2000). Outro problema frequente é a falta de equipamentos de laboratório nas escolas (LINGUANOTO, 1987; PAGOTTO; VIANA, 1991; SILVA; ZANON, 2000). Com isso, o tema das atividades experimentais deve ser escolhido de forma a utilizar equipamentos básicos ou materiais substitutos encontrados no ambiente escolar de baixo custo. 
Diante dos problemas expostos e da importância dos experimentos na aprendizagem significativa, foi escolhido um tema de Ciências Naturais para elaboração e teste de um roteiro a cerca de um experimento multidisciplinar para melhor entendimento do tema Osmose, conteúdo da disciplina de Biologia do Ensino Médio. O roteiro tem por objetivo tornar o experimento mais participativo, sem que o professor precise interferir na atividade, onde, deixa-se boa parte da responsabilidade de adquirir o conhecimento com o estudante.

\section{MATERIAL E MÉTODOS}

\subsection{OSMOSE}

A osmose é um assunto abordado na disciplina de Biologia que corresponde a um mecanismo de transporte celular que ocorre entre dois meios que apresentam diferença de concentração de soluto (TAIZ; ZEIGER, 2009a). O meio que apresenta maior concentração de soluto é chamado de meio hipertônico e o segundo meio, que apresenta uma menor concentração é chamado de meio hipotônico (CORRÊA, 2009). Os dois meios devem estar em contato separados por uma membrana não permeável ao soluto. O transporte do solvente é governado pela diferença de pressão entre os meios, no qual o meio hipertônico apresenta maior pressão comparado ao meio hipotônico. Com esta diferença de pressão o solvente será deslocado entre os meios.

A osmose ocorre sem o gasto de energia (TAIZ; ZEIGER, 2009a). O transporte de solvente entre os meios ocorrerá até se obter dois meios de mesma concentração de soluto, chamado de meios isotônicos. Nas células vegetais podemos encontrar este transporte na raiz, possibilitando a absorção de água do solo e transporte dessa para a copa das árvores, mesmo a alguns metros de altura. Nesse caso, ocorre o acúmulo de sais nas células da raiz, tornando possível a passagem da água para o interior das células da raiz e diferenças de sacarose entre as células das raízes a as folhas governam o transporte da água dentro das plantas. Outro local que podemos observar o transporte via osmose são nas células-guarda dos estômatos. Por diferença de potássio entre os meios, as células-guarda podem absorver água do meio, tornando- 
se túrgidas e com isso, ocorre a abertura do ostíolo, e o processo contrário também pode ocorrer (TAIZ; ZEIGER, 2009b).

O entendimento dos processos osmóticos é de extrema importância para os alunos para posterior compreensão de eventos biológicos, como por exemplo absorção e transporte de água nos vegetais, transporte em células vegetais, equilíbrio hídrico em organismos aquáticos, protozoários e plantas, trocas de substâncias entre células, entre outros eventos (AMABIS; MARTHO, 1996).

\subsection{ATIVIDADE PRÁTICA}

Os experimentos foram realizados no laboratório de Acarologia da Universidade Federal de Viçosa em Viçosa/MG, no mês de julho de 2018. Na elaboração do roteiro e execução do experimento foi levado em consideração a aquisição/utilização de materiais de baixo custo que viabilizassem a execução do experimento nas escolas que não possuem equipamentos, vidrarias e reagentes. Algumas avaliações foram realizadas utilizando equipamentos específicos para demonstrar numericamente a experiência, porém os professores podem utilizar outras medições para comprovação do fenômeno, conforme explicado a seguir e descritos no roteiro (Apêndice A).

Foram utilizados ovos de galinha, vinagre, açúcar e água. Além disso, uma balança e recipientes (copo plástico ou Béquer) de 200 e de $500 \mathrm{ml}$. A metodologia do trabalho foi adaptada de Amabis e Martho (1996). A membrana que envolve o ovo é semipermeável, permitindo que ocorra troca de líquido com o meio. Os ovos foram imersos em vinagre por um período de 24 a 48 horas para a remoção do carbonato de cálcio da casca. Após esse período, observou-se que toda a camada de carbonato de cálcio foi removida por uma reação química, restando apenas a camada coquilífera do ovo, membrana semipermeável. A reação química entre o carbonato de cálcio e o vinagre (ácido acético) produz acetato de cálcio, água e dióxido de carbono, como demonstrado na equação a seguir (HEMMER, 2017):

$$
\mathrm{CaCO}_{3(\mathrm{~s})}+2 \mathrm{CH}_{3} \mathrm{COOH} \rightarrow \mathrm{Ca}\left(\mathrm{CH}_{3} \mathrm{COO}\right)_{2(\mathrm{aq})}+\mathrm{H}_{2} \mathrm{O}_{(\mathrm{l})}+\mathrm{CO}_{2(\mathrm{~g})}
$$


Após o período 48 horas ou menos, foi possível observar que a reação citada acima não ocorria mais e que a membrana coquilífera apresenta uma elasticidade. Essa membrana foi utilizada como membrana permeável para observarmos o processo osmótico. Posteriormente, foram preparadas soluções com diferentes concentrações de açúcar com a finalidade de se estimar a pressão osmótica no interior do ovo através de uma equação de regressão.

Já se conhece a solubilidade de sacarose em água há muitos anos (TAYLOR, 1947). Conhecendo-se o coeficiente de solubilidade ou o grau de solubilidade da sacarose em água, foram preparadas quatro soluções com diferentes concentrações. O coeficiente de solubilidade foi definido por Feltre (2004) como sendo a quantidade de substância necessária para saturar uma quantidade de solvente. No nosso caso, o solvente é a água. A solubilidade da sacarose em água a 25ํㅡ é de 2,0741 gramas por cada grama de água (BUBINK; KADLEC, 1995). A partir desse dado de solubilidade foram preparadas cinco soluções de diferentes concentrações de saturação de sacarose: 0; 25; 50 e 100\% de saturação.

Após a preparação das soluções, os ovos (sem a casca) foram pesados. Posteriormente, esses foram submersos em soluções de sacarose com diferentes concentrações, de acordo com os tratamentos. Após 24 horas das trocas de solvente através da membrana do ovo, as unidades experimentais foram retiradas da solução e pesadas novamente. Através da diferença de peso, antes e após a submersão, foi possível determinar o fluxo de solvente entre as duas soluções.

Utilizou-se o delineamento experimental inteiramente casualizado com cinco tratamentos e cinco repetições. Portanto, o experimento continha vinte e cinco unidades experimentais. Os dados obtidos foram submetidos a análise de variância e quando significativos, à análise de regressão com a utilização de equação de regressão do software estatístico R 2.15.1 (R Development Core Team 2017). 


\section{RESULTADOS E DISCUSSÃO}

Após 24 horas de contato com a solução de sacarose, já foi possível observar a troca de solvente entre os meios. A membrana permeável do ovo permitiu a passagem do solvente do interior do ovo para a solução de sacarose, o que pode ser percebido pela variação do volume do ovo, percepção visual, e esta troca foi confirmada através da verificação da perda de peso das unidades experimentais. $O$ contrário também ocorreu, ou seja, houve aumento de peso, influxo de solvente, o qual ocorreu na concentração zero de sacarose.

A partir dos dados (Tabela 2) foi possível estimar uma equação de regressão linear simples significativa entre a molaridade de sacarose e a variação percentual do peso dos ovos (g.l. $=1 ; F=115,18 ; p<0.005 ; R^{2}=0.85$ ) (Figura 1).

Figura 1 -Variação do peso do ovo em função da molaridade de sacarose da solução.

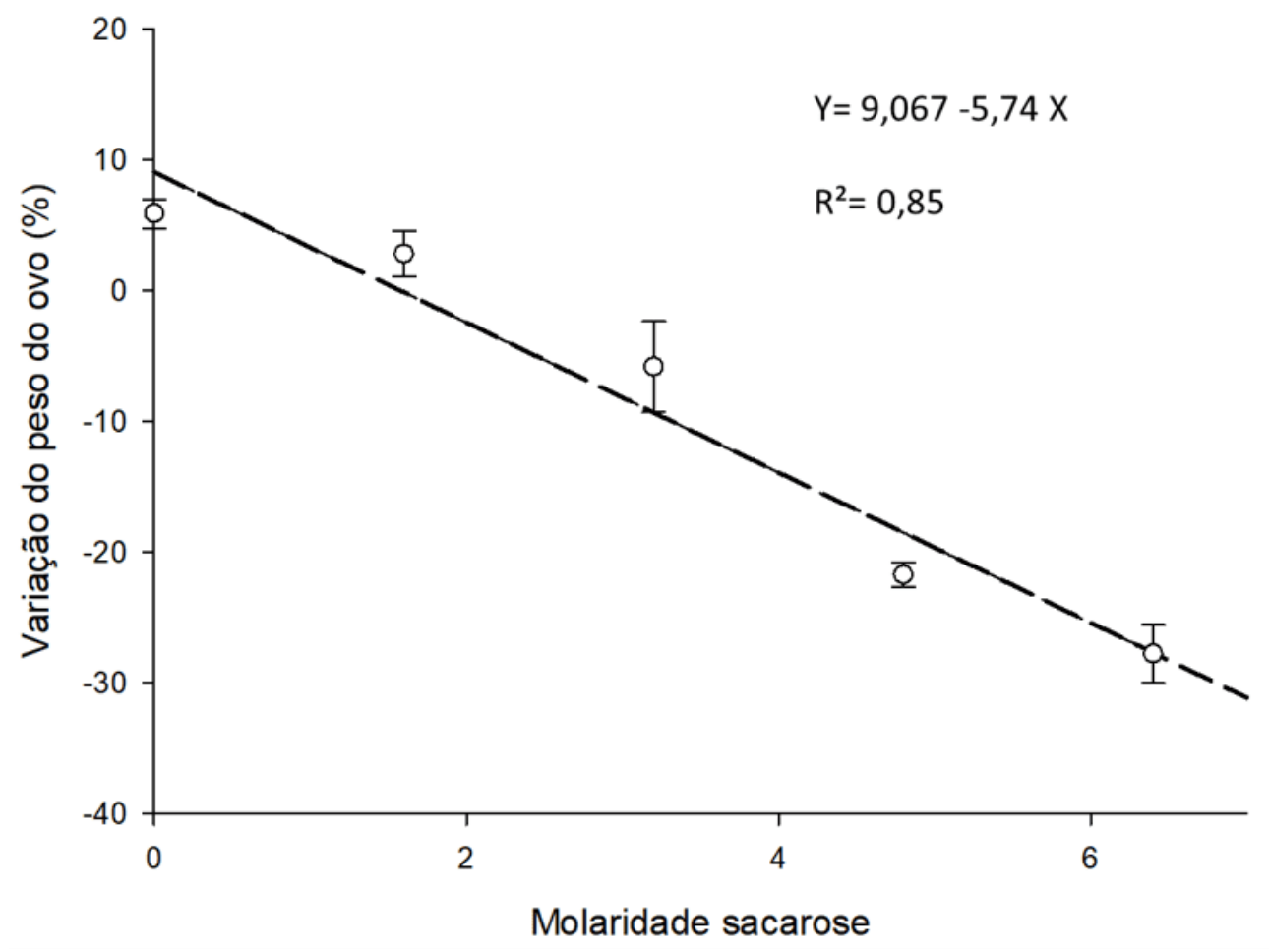

Fonte: Do autor. 
A concentração de solutos no interior do ovo pode ser estimada equivalente a em 1,66 $\mathrm{M}$ de sacarose, de acordo com a equação ajustada da curva. Com a modelagem da curva de regressão é possível aplicar conceitos de matemática e biologia em um único experimento. A outra aplicação do experimento seria a informática, com a utilização de planilhas eletrônicas ou software para ajuste da equação de regressão.

A figura 1 representa a parte gráfica dos dados, dando ênfase na interdisciplinaridade do experimento. Com os dados do experimento, os professores podem construir o gráfico com os alunos junto com o professor de matemática e em um outro momento com o professor de informática. O gráfico nesse trabalho demonstra a possibilidade de interdisciplinaridade na atividade experimental da proposta. Os dados (números) apresentados no gráfico apresentam uma importância pequena comparado com a possibilidade de construção do mesmo. É esperado que os professores construam o gráfico com a turma. Os professores não devem atentar-se para os valores do gráfico apresentado acima, mas sim para a importância do gráfico, da aplicação dos conhecimentos matemáticos e de informática para construção do mesmo, a não ser que julguem importante a estimativa da concentração molar no interior dos ovos.

Em primeiro momento é sugerido aos professores que ao final do experimento, os alunos façam uma análise qualitativa do fenômeno através da observação das unidades experimentais. Nesse momento, não é recomendado utilizar equipamentos ou outros meios para a quantificação da ocorrência da osmose, mas apenas observar. Essa sugestão surge do que é colocado por Ludke e André:

A observação constitui um dos principais instrumentos de coleta de dados nas abordagens qualitativas. A experiência direta é o melhor teste de verificação da ocorrência de um determinado assunto. O observador pode recorrer aos conhecimentos e experiências pessoais como complemento no processo de compreensão e interpretação do fenômeno estudado. A observação permite também que o observador chegue mais perto da perspectiva dos sujeitos e se revela de extrema utilidade na descoberta de aspectos novos de um problema. Por último, a observação permite a coleta de dados em situações em que é 
impossível estabelecer outras formas de levantamento ou outras formas de comunicação (LUDKE; ANDRÉ, 2011, p.45).

Com essa abordagem, será possível tornar a atividade ainda mais interativa, estimulando a participação de todos os alunos, uma vez que a observação não necessita de equipamentos e não limitará o número de alunos formulando as afirmações a respeito do ocorrido. A utilização de equipamento aborda o lado quantitativo do experimento, mas acredita-se que a abordagem quantitativa não é a única forma de exploração dos dados. Acredita-se que a parte qualitativa e quantitativa do experimento se completa, reafirmando o aprendizado. Com isso, nas escolas que não tenham balanças pode-se realizar o experimento e fazer uma análise qualitativa da ocorrência da osmose.

A experimentação é uma metodologia efetiva para o ensino de conteúdo de biologia conforme demonstrado por diversos autores (ARAUJO et al., 2014; SANTOS; BASTOS, 2018). De fato, a observação de fenômenos através de experimentos é de extrema importância para a aprendizagem, desde que alinhemos a prática com o conteúdo teórico. Nesse contexto, pensamos que o roteiro elaborado nesse trabalho sirva de modelo para as aulas experimentais de biologia e que inspirarão os professores de biologia e de outras áreas a explorarem ainda mais as suas aulas práticas. Essa nova abordagem do conteúdo, com certeza terá um impacto positivo sobre a aprendizagem dos estudantes. No entanto, sabe-se que essas práticas experimentais em muitos casos são dispendiosas, porém o resultado ao final é extremamente gratificante.

Jacob et al. (2009) demonstraram a efetiva importância dos experimentos construtivistas para o ensino de biologia em turmas do ensino médio. Através de suas atividades, os autores demonstraram que a maioria dos alunos mesmo após as aulas expositivas sobre os temas abordados nos experimentos não sabia responder questões simples e diretas sobre o assunto. Porém, após a participação dos alunos em práticas construtivistas, a média de acertos sobre o conteúdo abordado nos experimentos comparado aos acertos da turma que não realizou o experimento, variou entre $222 \%$ e $1150 \%$. No trabalho citado anterior, os autores demonstraram que entre 
os 11 temas sobre biologia abordados com as turmas de 1 e $3^{\circ}$ ano do ensino médio, houve uma diferença da assimilação do conteúdo com as práticas. Os autores não trabalharam com o tema osmose, por isso não podemos inferir qual o efeito da prática proposta nesse trabalho sobre a aprendizagem dos alunos. Entretanto, levando-se em consideração o incremento na média da turma trabalhada pelos autores, podemos esperar um ganho significativo na aprendizagem com a aplicação da prática aqui proposta.

Os alunos aceitam a metodologia dos experimentos e muitos relatam a importância da teoria-prática para a formação/aprendizagem dos conteúdos de biologia. Esperase que a prática proposta possa além de auxiliar na aprendizagem de biologia, possa instigar a busca pela resolução dos problemas matemáticos propostos, tanto utilizando calculadoras e matrizes, quanto utilizando ferramentas computacionais. Dessa forma, aplicaremos uma prática verdadeiramente multidisciplinar.

Existem na literatura outros experimentos para demonstração de osmose, entretanto o trabalho aqui apresentado leva em consideração a multidisciplinaridade da prática, com o envolvimento dos conteúdos de biologia, matemática e informática. Além do mais, o roteiro do experimento segue com uma lista de questionamentos para tornar a prática construtivista e não apenas uma prática com superação de etapas seguidas. Sabe-se que a aplicação de experimentos multidisciplinares pode apresentar algumas vantagens para os professores como, por exemplo, rateio dos custos com o experimento, maior tempo para observação dos fenômenos e discussão dos resultados. Além do mais, quando se trabalha de forma multidisciplinar é possível demonstrar nesse caso, a aplicação prática dos diferentes conteúdos em um único experimento.

Conforme proposto nos objetivos específicos, segue a Tabela 1 a ficha de avaliação do experimento e a Tabela $2 \mathrm{com}$ os resultados do experimento piloto realizado durante esse trabalho. Os docentes podem utilizar os dados do experimento como ponto de discussão caso não disponham de equipamentos e materiais, nesse caso, a aula se torna uma discussão dos dados. Dessa forma, será possível trabalhar a parte quantitativa dos dados, envolvendo as áreas de matemática e informática. 
Tabela 1 - Ficha para tabulação dos dados.

\begin{tabular}{|l|l|l|l|l|l|}
\hline Molaridade & Grupo & $\begin{array}{l}\text { Massa } \\
\text { inicial } \\
\text { (g) }\end{array}$ & $\begin{array}{l}\text { Massa } \\
\text { final } \\
\text { (g) }\end{array}$ & $\begin{array}{l}\text { Variação } \\
\text { da } \\
\text { massa } \\
\text { (g) }\end{array}$ & $\begin{array}{l}\text { Variação } \\
\text { percentual da } \\
\text { massa (\%) }\end{array}$ \\
\hline $\mathbf{0}$ & 1 & & & & \\
\hline $\mathbf{0}$ & 2 & & & & \\
\hline $\mathbf{0}$ & 3 & & & & \\
\hline $\mathbf{1 , 6}$ & 1 & & & & \\
\hline $\mathbf{1 , 6}$ & 2 & & & & \\
\hline $\mathbf{1 , 6}$ & 3 & & & & \\
\hline $\mathbf{3 , 2}$ & 1 & & & & \\
\hline $\mathbf{3 , 2}$ & 2 & & & & \\
\hline $\mathbf{3 , 2}$ & 3 & & & & \\
\hline $\mathbf{4 , 8}$ & 1 & & & & \\
\hline $\mathbf{4 , 8}$ & 2 & & & & \\
\hline $\mathbf{4 , 8}$ & 3 & & & & \\
\hline $\mathbf{6 , 4}$ & 1 & & & & \\
\hline $\mathbf{6 , 4}$ & 2 & & & & \\
\hline $\mathbf{6 , 4}$ & 3 & & & & \\
\hline
\end{tabular}

Fonte: Do autor.

Novamente ressalta-se a importância da Tabela 2 apenas para possibilitar a construção do gráfico, dando maior importância para a prática interdisciplinar da construção do mesmo com os conceitos de osmose do que a parte numérica do experimento. 
Tabela 2 - Ficha com os dados do experimento piloto.

\begin{tabular}{|c|c|c|c|c|c|}
\hline Molaridade & Grupo & $\begin{array}{l}\text { Massa } \\
\text { inicial } \\
(\mathrm{g})\end{array}$ & $\begin{array}{l}\text { Massa } \\
\text { final } \\
(g)\end{array}$ & $\begin{array}{l}\text { Variação } \\
\text { da } \\
\text { massa } \\
\text { (g) }\end{array}$ & $\begin{array}{l}\text { Variação } \\
\text { percentual } \\
\text { da massa } \\
(\%)\end{array}$ \\
\hline 0 & 1 & 91,70 & 93,50 & 1,80 & 1,96 \\
\hline 0 & 2 & 82,30 & 90,40 & 8,10 & 9,84 \\
\hline 0 & 3 & 84,00 & 88,96 & 4,96 & 5,90 \\
\hline 0 & 4 & 86,00 & 91,07 & 5,07 & 5,90 \\
\hline 0 & 5 & 87,00 & 92,13 & 5,13 & 5,90 \\
\hline 1,6 & 1 & 82,30 & 86,10 & 3,80 & 4,62 \\
\hline 1,6 & 2 & 90,90 & 95,40 & 4,50 & 4,95 \\
\hline 1,6 & 3 & 93,70 & 89,40 & $-4,30$ & $-4,59$ \\
\hline 1,6 & 4 & 78,00 & 82,90 & 4,90 & 6,28 \\
\hline 1,6 & 5 & 90,00 & 92,62 & 2,62 & 2,91 \\
\hline 3,2 & 1 & 83,20 & 76,00 & $-7,20$ & $-8,65$ \\
\hline 3,2 & 2 & 79,60 & 72,00 & $-7,60$ & $-9,55$ \\
\hline 3,2 & 3 & 90,50 & 81,40 & $-9,10$ & $-10,06$ \\
\hline 3,2 & 4 & 80,80 & 72,30 & $-8,50$ & $-10,52$ \\
\hline 3,2 & 5 & 82,00 & 89,95 & 7,95 & 9,69 \\
\hline 4,8 & 1 & 81,20 & 64,60 & $-16,60$ & $-20,44$ \\
\hline 4,8 & 2 & 95,90 & 71,30 & $-24,60$ & $-25,65$ \\
\hline 4,8 & 3 & 82,60 & 66,80 & $-15,80$ & $-19,13$ \\
\hline 4,8 & 4 & 84,00 & 65,74 & $-18,26$ & $-21,74$ \\
\hline 4,8 & 5 & 86,00 & 67,30 & $-18,70$ & $-21,74$ \\
\hline 6,4 & 1 & 93,00 & 59,30 & $-33,70$ & $-36,24$ \\
\hline 6,4 & 2 & 84,00 & 60,50 & $-23,50$ & $-27,98$ \\
\hline 6,4 & 3 & 87,60 & 69,50 & $-18,10$ & $-20,66$ \\
\hline 6,4 & 4 & 80,00 & 59,00 & $-21,00$ & $-26,25$ \\
\hline 6,4 & 5 & 88,00 & 63,55 & $-24,45$ & $-27,78$ \\
\hline
\end{tabular}


Fonte: Do autor.

O apêndice B apresenta um guia de possíveis perguntas para discussão durante o pré e pós experimento como uma ferramenta útil para fixação do conteúdo estudado. Essas perguntas nortearão a execução do experimento, lembrando-se sempre da flexibilidade de realização do experimento permitindo de fato a experimentação pelos discentes. O questionário foi elaborado para tornar o experimento ainda mais significativo, pois o aluno ao ser questionado, passa a elaborar hipótese para a solução do problema e não apenas aplica o que é pedido. É necessário permitir que o aluno possa tomar as escolhas de como realizar o experimento para tornar o experimento potencialmente associativo e não uma mera realização de "receita de bolo". Os experimentos que seguem roteiros fixo, engessados, não corroboram com o aprendizado significativo dos alunos e apenas fazem cumprir a carga horária prática prevista no plano de ensino.

O experimento proposto no trabalho se executado conjuntamente com o questionário tornará possível obter maior efetividade no ensino do conteúdo. A utilização do modelo de ensino aprendizagem significativo estimula o raciocínio lógico e curiosidade dos discentes, ultrapassa os limites da escola e forma cidadãos mais críticos.

\section{CONCLUSÕES}

O roteiro e o experimento foram elaborados e testados para aula prática sobre osmose a ser executado na disciplina de Biologia com os alunos do Ensino Médio ou poderá ser executado uma prática multidisciplinar com docentes da área de Biologia, Matemática e Informática.

Um questionário foi elaborado para ser discutido com os alunos durante a experimentação, como uma ferramenta de estudo e aplicação da metodologia de aprendizagem significativa.

Uma ficha para avaliação da prática foi elaborada, com a finalidade de entender se realmente a metodologia empregada vai de encontro com a aprendizagem 
significativa. O questionário deve ser aplicado aos alunos de forma a estimular outras práticas, visto que essas muito contribuem com o aprendizado.

O experimento proposto vem de encontro a aprendizagem significativa, com todos os benefícios desse modelo de ensino. Espera-se que a utilização de todas as ferramentas elaboradas no trabalho possa estimular a participação dos discentes na aula prática e como resultado possam incrementar a assimilação do conteúdo.

\section{REFERÊNCIAS}

ALVES, VAGNER CAMARINI; STACHAK, MARIELI. A Importância de Aulas Experimentais no Processo de Ensino-Aprendizagem em Física: Eletricidade. In: XVI SIMPÓSIO NACIONAL DE ENSINO DE FÍSICA- SNEF. Universidade do Oeste Paulista - UNOESTE, 2005, Presidente Prudente: São Paulo. Anais eletrônicos... São Paulo: UENF. $2005 . \quad$ Disponível em: < http://www.uenf.br/Uenf/Downloads/LCFIS_7859_1276288519.pdf>. Acesso em: 10/10/2018.

AMABIS, JOSÉ MARIANO; MARTHO, GILBERTO RODRIGUES. Biologia das células. In: AMABIS, J.M.; MARTHO, G. R. Temas de biologia: propostas para desenvolver em sala de aula. Número 3. Trabalhando temas fundamentais: osmose. Rio de Janeiro: Moderna, 1996.

ARAÚJO, MAURO SÉRGIO TEIXEIRA; ABIB, MARIA LÚCIA VITAL SANTOS. Atividades experimentais no ensino de física: diferentes enfoques, diferentes finalidades. Revista Brasileira de Ensino de Física, v. 25, n. 2, p. 176-194, 2003.

ARAUJO, NAILTON SOUZA; NASCIMENTO, ANA PAULA COSTA; BEZERRA, MÁRICA MARIA LEOCÁDIO; ALVES, MARIA HELENA. Atividade prática sobre osmose: a importância de contextualizar a experimentação no ensino de biologia. In: CONGRESSO NACIONAL DE EDUCAÇÃO. Anais eletrônicos... Campina Grande: Realize. 2014. Disponível em: http://www.editorarealize.com.br/revistas/conedu/trabalhos/Modalidade_1datahora_0 
9_08_2014_15_21_06_idinscrito_4622_5ea1cd7b6410fd29faf29f89888a4884.pdf>. Acesso em: 10/10/2018.

ARRUDA, SÉRGIO MELLO.; LABURÚ, CARLOS EDUARDO. Considerações sobre a função do experimento no ensino de Ciências. Pesquisa em ensino de Ciências e Matemática, n.3, p. 14-24, 1996.

AUSUBEL, DAVID PAUL, NOVAK, JOSEPH DONALD; HANESIAN, HELEN. Psicologia educacional. Rio de Janeiro: Interamericana, 1980. 626 p.

BRASIL. Ministério da Educação (MEC), Secretaria de Educação Básica. Parâmetros Curriculares Nacionais do Ensino Médio (PCNEM). Ciências da Natureza, Matemática e suas Tecnologias, 1999. Disponível em: $<$ http://portal.mec.gov.br/seb/arquivos/pdf/ciencian.pdf >. Acesso em: 10/10/2018.

BUBNIK, ZDENEK; KADLEC, PAVEL. Sucrose solubility. In: Mathlouthi M., Reiser P. (eds) Sucrose. Springer, Boston, MA, 1995. p. 101-125.

BONWELL, CHARLES C.; EISON, JAMES A. Active learning: creating excitement in the classroom. Washington, DC: Eric Digests, 1991. Publication Identifer ED340272. Disponível em: http://www.eric.ed.gov/PDFS/ED340272.pdf>. Acesso em: 10/10/2018.

CAPELETTO, ARMANDO JOSÉ. Biologia e Educação ambiental: Roteiros de trabalho. São Paulo: Ática, 1992. 224 p.

CARRAHER, DAVID WILLIAM.; CARRAHER, TERESINHA NUNES; SCHLIEMANN, ANALÚCIA DIAS. Caminhos e descaminhos no ensino de ciências. Ciência e cultura, v. 37 , n. 6 , p. 889-896, 1985.

CORRÊA, EDSON RIBEIRO. Fisiologia Vegetal. São Cristóvão: Universidade Federal de Sergipe, CESAD2009. 2009. 14 p.

FAZENDA. IVANI CATARINA ARANTES. Interdisciplinaridade: história, teoria e pesquisa. 4. ed. Campinas: Papirus, 1994. 144p. 
FELTRE, RICARDO. Química: Físico-Química. v. 2. 6 ed. São Paulo: Moderna, 2004. $417 p$.

FRACALANZA, HILÁRIO; AMARAL, IVAM AMOROSIO; GOUVEIA, MARILEY SIMÕES FLÓRIA. O Ensino de Ciências no 1 grau. São Paulo: Atual. 1986, 124 p.

GALIAZZI, MARIA CARMO; ROCHA, JUSSELI MARIA BARROS; SCHMITZ, LUIZ CARLOS; SOUZA, MOACIR LANGONI; GIESTA, SÉRGIO; GONÇALVES, FÁBIO PERES. Objetivos das atividades experimentais no ensino médio: a pesquisa coletiva como modo de formação de professores de Ciências. Ciência \& Educação. v. 7, n. 2, p. 249-263, 2001

GRISALES FRANCO, LINA MARÍA; GONZÁLEZ AGUDELO, ELVIA MARÍA. El saber sabio y el saber enseñado: un problema para la didáctica universitaria. Educación y Educadores. v. 12, n. 2, p. 11-28, jul./dez. 2009.

GUIMARÃES, CLEIDSON CARNEIRO. Experimentação no ensino de química: caminhos e descaminhos rumo à aprendizagem significativa. Química nova na escola, v. 31, n. 3, p. 198-202, 2009.

HEMMER, SEAN. Why does vinegar affect limestone? Sciencing, Santa Mônica, abril 2017. Disponível em: <http://sciencing.com/vinegar-affect-limestone-7888211.html>. Acesso em: 10/10/2018.

HODSON, DEREK. Mini-special issue: taking practical work beyond the laboratory. International Journal of Science Education, v. 20, n. 6, p. 629-632, 1998.

JACOB, PRISCILA LIMA; BARBOZA; GIUSEPPE FERNANDES OLIVEIRA; MEDEIROS, ZORAIDA MARIA DAVINO; PEREIRA, MARSÍLVIO GONÇALVES; LUCENA, VERA LÚCIA ARAÚJO. Formação de conceitos científicos em biologia através de atividades teórico-práticas. In: XI Encontro de Extensão e XII Encontro de Iniciação à Docência. Anais eletrônicos... Paraíba. 2009. Disponível em: <http://www.prac.ufpb.br/anais/XlenexXIlenid/enex/TRABALHO_COMPLETO_XI_EN EX/4.EDUCACAO/4CCENDSEPEX01.doc>. Acesso em: 10/10/2018. 
JAPIASSU, HILTON. Interdisciplinaridade e patologia do saber. Rio de Janeiro: Imago, 1976. $221 \mathrm{p}$.

LEÃO, DENISE MARIA MACIEL. Paradigmas contemporâneos de educação: escola tradicional e escola construtivista. Cadernos de pesquisa, v. 107, p. 187-206, 1999.

LIMA, MARIA EMILIA CAIXETA CASTRO; JÚNIOR, ORLANDO GOMES AGUIAR; BRAGA, SELMA AMBROSINA MOURA Aprender ciências: um mundo de materiais. Belo Horizonte: Ed. UFMG. 1999. 78 p.

LINGUANOTO, MARIA. O que está acontecendo com o ensino de Química no Segundo Grau. In: CONFERÊNCIA INTERNACIONAL DE EDUCAÇÃO QUÍMICA, 1987, São Paulo. Anais... São Paulo, 1987. p. 265-276.

LUDKE, MENGA; ANDRÉ, MARLI ELIZA DALMAZO AFONSO. Pesquisa em educação: abordagens qualitativas. Em Aberto, v. 5, n. 31, p. 42-49, 2011.

MEZZARI, ADELINA. O uso da aprendizagem baseada em problemas (ABP) como reforço ao ensino presencial utilizando o ambiente de aprendizagem Moodle. Revista Brasileira de Educação Médica, v. 35, n. 1, p.114-121, 2011.

MORAES, ROQUE. O significado da experimentação numa abordagem construtivista: O caso do ensino de ciências. In: BORGES, R. M. R.; MORAES, R. (Org.) Educação em Ciências nas séries iniciais. Porto Alegre: Sagra Luzzato. 1998. p. 29-45.

MOREIRA, MARCO ANTONIO; MASINI, ELCIE FORTES SALZANO. Aprendizagem significativa: a teoria de David Ausubel. São Paulo: Centauro 2001. 111 p.

MOREIRA, MATEUS LUÍS; DINIZ, RENATO EUGÊNIO SILVA DINIZ. O laboratório de Biologia no Ensino Médio: infraestrutura e outros aspectos relevantes. In: Universidade Estadual Paulista - Pró Reitoria de Graduação (Org.). Núcleos de Ensino. São Paulo: Editora da UNESP, v. 1, p. 295-305, 2003.

PAGOTTO, CARMEN LUCIA ARAUJO COSTA; VIANA, L.M. A falsa imagem da Química. Ciência Hoje, v. 13, n. 74, p. 72-73, 1991. 
PELIZZARI, ADRIANA.; KRIEGL, MÁRCIA LURDES; BARON, MÁRCIA PIRIH; FINCK, NELCY TERESINHA LUBI; DOROCINSKI, SOLANGE INÊS. Teoria da aprendizagem significativa segundo Ausubel. Revista PEC, v. 2, n. 1, p. 37-42, 2002.

R Development Core Team. R: a language and environment for statistical computing. R Foundation for Statistical Computing, Vienna, Austria. 2017.

SÁ, MÁRIO GOMES; MOURA, GUILHERME LIMA. A crítica discente e a reflexão docente. Cadernos EBAPE.BR, v. 6, n. 4, p. 1-10, 2008.

SANTOS, MARCELO G.; BASTOS, WAGNER G. Medido a pressão osmótica de soluções em osmômetro construído com membrana de ovos de aves. Químa Nova na Escola. v. 40, n. 3, p. 209-213, 2018.

SILBERMAN, MEL. Active learning: 101 strategies do teach any subject. Massachusetts: Pearson, 1996. 216 p.

SILVA, L.H.A.; ZANON, LENIR BARROSO. A experimentação no ensino de ciências. In: SCHNETZLER, R.P.; ARAGÃO, R.M.R. Ensino de Ciências: Fundamentos e Abordagens. Piracicaba: CAPES/UNIMEP, 2000. p. 120-153.

SMITH, K. A. Experimentação nas Aulas de Ciências. In: CARVALHO, A. M. P.; VANNUCCHI, A. I.; BARROS, M.A.; GONÇALVES, M.E.R.; REY, R.C. Ciências no Ensino Fundamental: O conhecimento físico. São Paulo: Editora Scipione.1998. p. 2223.

TAIZ, LINCON; ZEIGER, EDUARDO. Respostas à luz azul: movimentos estomáticos e morfogênese. In: TAIZ, LINCON; ZEIGER, EDUARDO. Fisiologia vegetal. 4. ed. Porto Alegre: Artmed, 2009a. p. 429-447.

TAIZ, LINCON.; ZEIGER, EDUARDO. Transporte de soluto. In: TAIZ, LINCON; ZEIGER, EDUARDO. Fisiologia vegetal. 4. ed. Porto Alegre: Artmed, 2009b. p. 131139. 
TAYLOR, MILLICENT. The solubility at high temperatures of pure sucrose in water. Journal of the Chemical Society, p. 1678-1683, 1947.

VIANNA, ILCA OLIVEIRA ALMEIDA. Metodologia do trabalho científico: um enfoque didático da produção científica. São Paulo: EPU. 2001. 304 p.

\section{APÊNDICE A - ROTEIRO DA ATIVIDADE EXPERIMENTAL}

\section{Objetivo:}

Observar o transporte passivo entre os meios com diferentes concentrações e definir a concentração osmótica no interior do ovo.

\section{Material:}

- Béquer de $500 \mathrm{ml}$ (ou recipiente de tamanho compatível ou superior);

- Béquer de $250 \mathrm{ml}$ (ou recipiente de tamanho compatível ou aproximado);

- Balança que tenha precisão de 0,1 g (outras poderão ser utilizadas, mas com possíveis erros na quantificação);

- Vinagre $(1000 \mathrm{ml})$;

- Ovos de galinha;

- Açúcar;

- Caneta para retroprojetor.

Procedimento:

1. Coloque o vinagre no recipiente maior e adicione os ovos. Caso utilize muitos ovos, separe em dois recipientes de forma a permitir o contato do vinagre com toda a superfície da casca dos ovos.

2. Deixe os ovos por um período de 24 a 48 h no vinagre;

3. Prepare as soluções com diferentes concentrações molares de sacarose:

a) T1: controle -0 Molar - água pura;

b) T2: 1,6 Molar: 55 gramas de açúcar dissolvidos em $100 \mathrm{ml}$ de água; 
c) T3: 3,2 Molar: 110 gramas de açúcar dissolvidos em $100 \mathrm{ml}$ de água;

d) T4: 4,8 Molar: 165 gramas de açúcar dissolvidos em $100 \mathrm{ml}$ de água;

e) T5: 6,4 Molar: 220 gramas de açúcar dissolvidos em $100 \mathrm{ml}$ de água;

Observação: a quantidade de solução vai depender do número de repetições (grupos). Recomenda-se pelo menos três grupos.

Sugere-se que os copos com as diferentes concentrações sejam misturados e marcados com letras para que ao final da experiencia os alunos possam discutir qual letra corresponde a cada concentração, baseado nos resultados encontrados. Esperase que com essa mistura, tenha-se um experimento mais interativo e não apenas mecânico.

4. Após o período de reação do carbonato de cálcio com o ácido acético, lave os ovos com água corrente e seque-o;

5. Pese os ovos separadamente e adicione em copos marcados com numeração e tratamentos (letras);

6. Deixe os ovos submersos na solução correspondente ao tratamento por um período de $24 \mathrm{~h}$, para que ocorra o transporte de solvente;

7. Faça uma análise qualitativa do ocorrido. Observe e compare o volume dos ovos das diferentes soluções. Essa é uma abordagem qualitativa possível de ser aplicada em escolas que não possuem equipamentos para a abordagem quantitativa.

8. Após o procedimento anterior, pese os ovos separadamente e anote os valores na planilha no apêndice;

9. Os grupos devem compartilhar os valores obtidos, de forma que todos tenham uma tabela totalmente preenchida com as repetições. A sugestão é que cada grupo faça uma repetição de cada tratamento. A quantidade de repetição vai depender da disponibilidade de ovos. Outra observação é que a planilha seja copiada no quadro e preenchida por integrantes dos diversos grupos, para que todos tenham acesso aos dados. 


\section{Discuta com os alunos}

1. Quais são os indicativos da ocorrência da reação entre o carbonato de cálcio e o ácido acético (vinagre)?

2. Quais são os indicativos da ocorrência do processo osmótico?

3. Quais são as estruturas relevantes para a ocorrência da osmose?

4. Quais são as substâncias envolvidas na osmose?

5. Qual é a curva de regressão que se ajusta aos dados?

6. Qual é a estimativa de molaridade no interior dos ovos?

7. Os mesmos resultados serão encontrados se utilizássemos sal?

8. Quais ajustes serão necessários para a utilização do sal?

9. Cite exemplos de processos osmóticos no dia a dia.

\section{APÊNDICE B - AVALIAÇÃO DE ATIVIDADES EXPERIMENTAIS}

1) Defina o que são aulas práticas? *Pergunta a ser realizada no dia anterior à prática.

2) Quais foram as práticas realizadas durante esse semestre? Onde foram realizadas (local, data, etc.). Conte um pouco dessas práticas.

3) O que você acha das aulas práticas?

4) Geralmente, os professores costumam realizar aulas práticas no laboratório da escola?

5) Quais as práticas que você já ouviu falar ou viu na internet ou televisão que achou interessante e gostaria de realizar?

6) Qual a sua nota para a aula prática realizada?

7) Ao final da prática, você acha que entendeu melhor o tema: Osmose?

[1] Doutor em Entomologia pela Universidade Federal de Viçosa, Docente do Instituto Federal de Educação, Ciência e Tecnologia do Amapá - Campus Porto Grande. 
Enviado: Fevereiro, 2020.

Aprovado: Fevereiro, 2020. 